\title{
Scrotal leiomyoma: a rare cause of scrotal swelling
}

\author{
P. A. Egharevba ${ }^{1 *}$, O. Omoseebi ${ }^{2}$, A. I. Okunlola ${ }^{1}$ and O. A. Omisanjo ${ }^{3}$
}

\begin{abstract}
Background: Leiomyomas are benign smooth muscle tumours predominantly found in the uterus. Rarely, they may be located in the ovaries, scrotum, bladder, lungs, vascular structures and spermatic cord.

Case presentation: We managed a 39-year-old man who presented with a year history of progressive right-sided hemiscrotal swelling. The right scrotal mass was excised, and histology showed scrotal leiomyoma.

Conclusion: Scrotal leiomyoma is very rare and challenging to diagnose pre-operatively as a cause of scrotal swelling, but it is amenable to surgical excision.
\end{abstract}

Keywords: Case report, Scrotal leiomyoma, Rare tumours, Scrotal swelling

\section{Background}

Leiomyomas are benign mesenchymal tumours that originate from smooth muscle cells. An overwhelming majority are found in the uterus [1]. Rarely, leiomyoma may occur in the ovaries, scrotum, bladder, lungs, vascular structures and spermatic cord [2]. Leiomyomas found in the skin and subcutaneous tissue can be classified based on their site of origin; piloleiomyoma when they arise from arrector pili muscles of hair follicles, angioleiomyoma from smooth muscle of blood vessel wall and genital leiomyoma which originate from smooth muscles of the vulva, scrotum and the myoepithelial cells of the nipple [3]. The genital leiomyomas are the least common of the extrauterine variety [4]. Scrotal leiomyoma was first described by Forsters in 1858 and is reported to be extremely rare [5]. Only 11 cases of scrotal leiomyoma were found out of 11,000 cases of benign and malignant tumours of the scrotum and its contents in a review done by Siegal and Gaffey [6]. We present a young man who was seen in our facility with a slowly progressive right

*Correspondence: peteregharevba@yahoo.com; peteregharevbag@gmail. com

${ }^{1}$ Department of Surgery, Federal Teaching Hospital, Ido-Ekiti, Ekiti State, Nigeria

Full list of author information is available at the end of the article scrotal swelling. Management and histopathological findings are highlighted.

\section{Case presentation}

A 39-year-old Yoruba native of Southwestern Nigeria was referred to the urology unit on account of a year history of progressive right hemiscrotal mass. He had occasional dull aching pain in the right hemiscrotum. There were no lower urinary tract symptoms, cough, drenching night sweats, fever or weight loss. Physical examination revealed a non-tender, firm right hemiscrotal mass about $6 \mathrm{~cm} \times 4 \mathrm{~cm}$ and inseparable from the ipsilateral testis. The left testis felt normal in size and consistency; inguinal lymph nodes were not palpable. A clinical diagnosis of suspected right testicular cancer was made. Scrotal Ultrasound scan reported a $4.9 \mathrm{~cm} \times 3.9 \mathrm{~cm}$ well-circumscribed mass with mixed echogenicity attached to the lower pole of the right testis with minimal vascularity. The right testis measured $3.1 \mathrm{~cm} \times 2 \mathrm{~cm} \times 3 \mathrm{~cm}$ and was superiorly displaced. The differential diagnoses were epidermoid cyst, germ cell tumour and adenomatoid tumour. The patient's complete blood count, serum $\beta$-human chorionic gonadotropin, $\alpha$-fetoprotein, blood chemistry were within normal limits. He subsequently had a right radical orchidectomy (Fig. 1) as a testicular malignancy could 


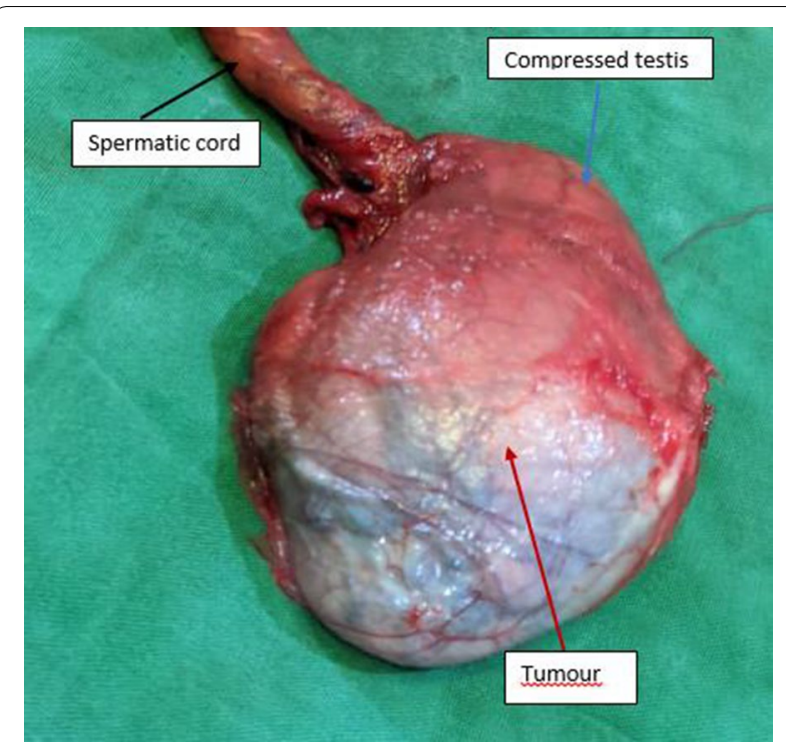

Fig. 1 Intra-operative specimen

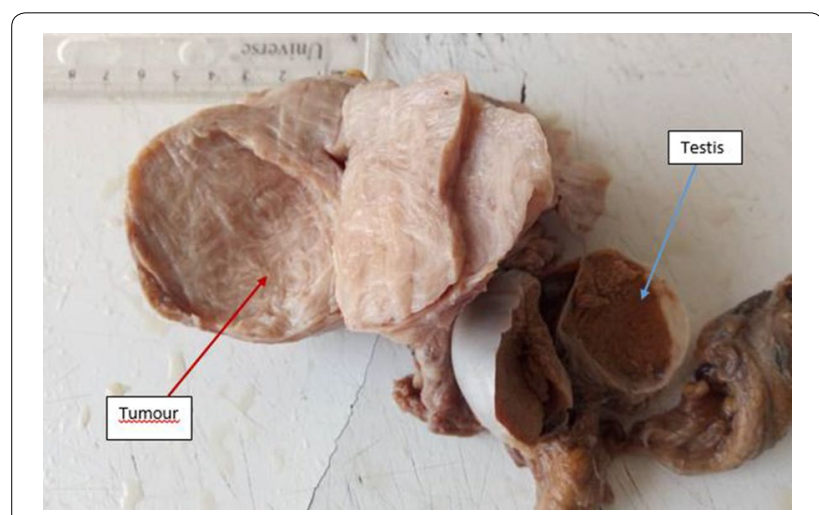

Fig. 2 Pathology specimen

not be ruled out. The post-operative recovery was uneventful, and he was discharged home.

Pathology report: Grossly, the mass was $7.5 \mathrm{~cm} \times 6.0 \mathrm{~cm} \times 5.0 \mathrm{~cm}$ in dimensions, displacing and compressing the testis which measured $4 \mathrm{~cm} \times 2.5 \mathrm{~cm} \times 2.0 \mathrm{~cm}$. Cut sections of the mass showed greyish white whorled surfaces while cut sections of the testis showed homogenous golden yellow surfaces (Fig. 2). Microscopic examination of the mass revealed interlacing bundles of smooth muscle fibres haphazardly arranged in whorls. The cells have regular nuclei and variable cytoplasm. There was no cytological atypia, necrosis or abnormal mitosis (less than 1 mitosis/10 high-power field seen). Also seen were many thin- and thick-walled blood vessels. Foci of calcification and hyaline degeneration were present. Sections of the testis showed poorly fixed testicular tissue composed of numerous seminiferous tubules lined by thin basement membrane with reduced population of spermatogenic cells. The interstitial leydig cells were unremarkable. The resection margins were free of tumour cells.

Immunohistochemical stains showed positive cytoplasmic expression of smooth muscle actin (SMA) and desmin filaments (Fig. 3a-d). The final histologic diagnosis was leiomyoma of the scrotal sac.

\section{Discussion}

Leiomyomas are benign tumours of smooth muscle predominantly found in the uterus. Very rarely, they may arise from the dartos muscle of the scrotum. Scrotal leiomyomas are more common in Caucasians between the fourth and sixth decades of life as solitary painless cutaneous lesions measuring $1-14 \mathrm{~cm}$ with an average diameter of $6.4 \mathrm{~cm} \mathrm{[3].} \mathrm{Typically,} \mathrm{the} \mathrm{patients}$ present at an average of 7.6 years from onset of mass due to its slow growing and asymptomatic nature [6].

However, our case was a Negro who presented at 39 years of age with occasional pain. He presented within 1 year of recognition of mass because of the associated pain and fear of having a malignancy. The scrotal ultrasound scan suggested a mass which was attached to the testis with differential diagnoses of epidermoid cyst, germ cell tumour and adenomatoid tumour. This heightened a suspicion of a testicular tumour which necessitated a radical orchidectomy since most solid testicular masses are malignant. Magnetic resonance imaging (MRI) has been found to provide additional and important information to scrotal ultrasound in detection and localization of scrotal tumours as reported by Cassidy et al. [7]. However, ultrasound is far cheaper and more readily available in our environment. Guthrie and Fowler found ultrasound to have $98 \%$ and $99.8 \%$ sensitivity and specificity, respectively, for testicular malignancy [8].

Benign smooth muscle tumours of the scrotum are classified either as typical or atypical leiomyoma. Four histologic criteria are used in this classification: (1) size $\geq 5 \mathrm{~cm}$ in widest diameter, (2) presence of infiltrating margins, (3) $\geq 5$ mitotic figures per 10 high-power fields and (4) moderate cytological atypia. Those with any one of these features are described as typical while tumours with two features are atypical leiomyoma [3, 9, 10]. The occurrence of three or more of these features renders such a leiomyosarcoma. The index case is a 


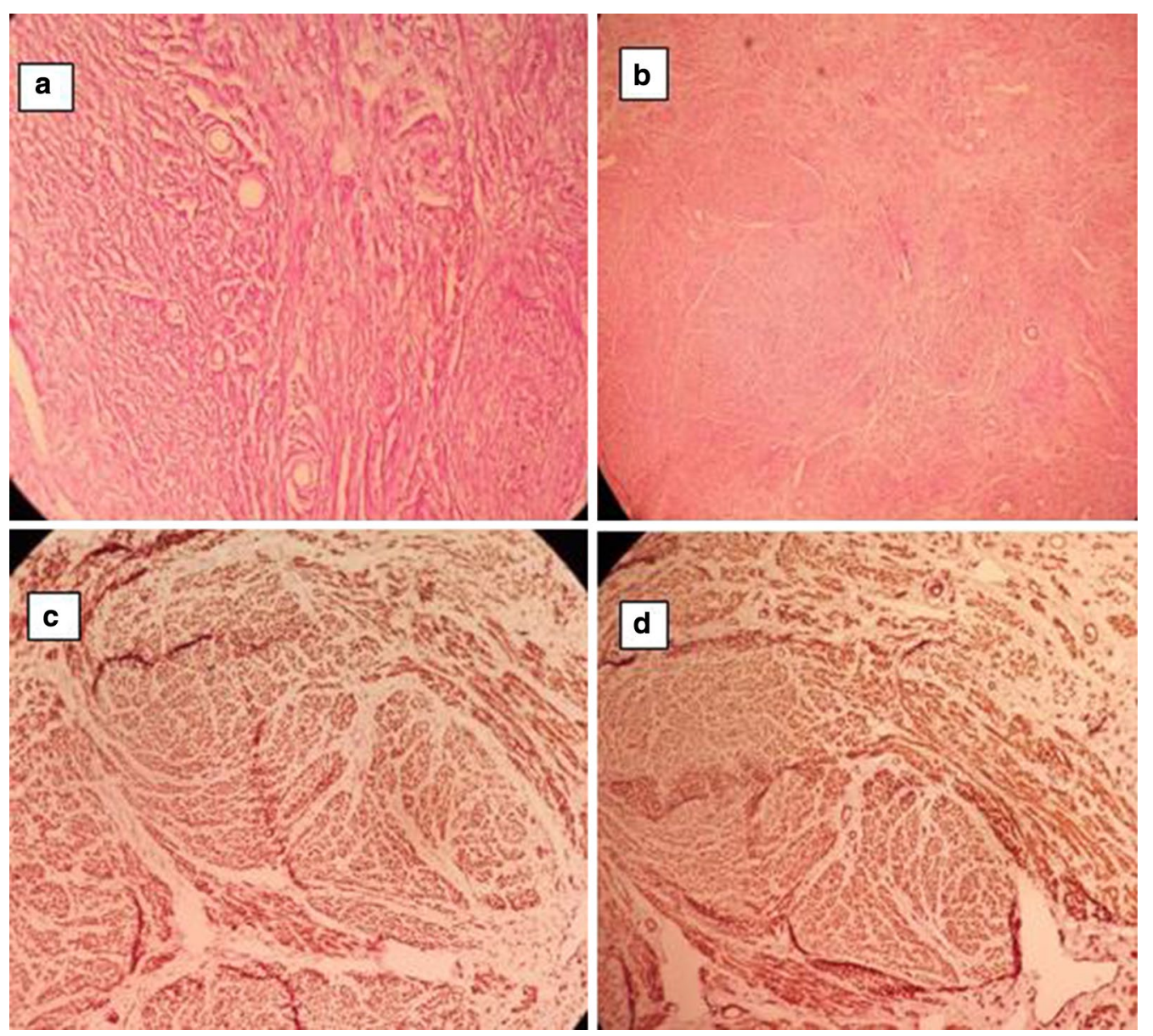

Fig. 3 Histology slides; a photomicrograph of the scrotal mass $\times 10$ magnification, b photomicrograph of scrotal mass $\times 4$ magnification, c immunohistochemistry Photomicrograph showing positive cytoplasmic expression of smooth muscle actin filament ( SMA $\times 10), \mathbf{d}$ photomicrograph showing immunohistological positive cytoplasmic expression of desmin filaments ( Desmin $\times 10$ )

typical leiomyoma, and the principal treatment is surgical excision.

\section{Conclusion}

Scrotal leiomyoma is a rare but known differential of scrotal mass. Pre-operative diagnosis is challenging, but surgical excision is sufficient for cure.

\section{Acknowledgements}

Department of Surgery, Federal Teaching Hospital Ido-Ekiti, Ekiti State, Nigeria,

\section{Authors' contributions}

PAE wrote manuscript and did literature search. $\mathrm{O}$ handled histopathological diagnosis and photomicrographs. AlO contributed to manuscript write-up and literature search. OAO proof-read and approved final version of manuscript. All authors have read and approved the manuscript.

\section{Funding}

No external funding available to disclose.

\section{Availability of data and materials} Not applicable.

\section{Ethics approval and consent to participate}

Human Research and Ethics Committee, Federal Teaching Hospital Ido-Ekiti, Nigeria. Protocol no. ERC/2020/06/23/382A.

\section{Consent for publication}

Written and informed consent was obtained from patient.

\section{Competing interests}

The authors declare no conflict of interest regarding this article.

\section{Author details}

${ }^{1}$ Department of Surgery, Federal Teaching Hospital, Ido-Ekiti, Ekiti State, Nigeria. ${ }^{2}$ Department of Anatomic Pathology, Federal Teaching Hospital, Ido-Ekiti, Ekiti State, Nigeria. ${ }^{3}$ Department of Surgery, Lagos State University Teaching Hospital, Ikeja, Lagos State, Nigeria.

Received: 20 July 2020 Accepted: 5 October 2020

Published online: 23 November 2020

\section{References}

1. Aluko T, Masi Z, Tomaszewski J, Germaine P (2018) Scrotal sac leiomyoma: case report of a rare benign scrotal mass. Radiol Case Rep 13(2):411-414 
2. Belis JA, Post GJ, Rochman SC, Franklin MD (1979) Genitourinary leiomyomas. Urology 13(4):424-429

3. Newman PL, Fletcher CDM (1991) Smooth muscle tumours of the external genitalia: clinicopathological analysis of a series. Histopathology 18(6):523-529

4. Aganovic L, Cassidy F (2012) Imaging of the scrotum. Radiol Clin N Am 50(6):1145-1165

5. Das AK, Bolick D, Little NA, Walther PJ (1992) Pedunculated scrotal mass: leiomyoma of scrotum. Urology 39(4):376-379

6. Siegal GP, Gaffey TA (1976) Solitary leiomyomas arising from the tunica dartos scroti. J Urol 116(1):69-71

7. Cassidy FH, Ishioka KM, McMahon CJ, Chu P, Sakamoto K, Lee KS et al (2010) MR imaging of scrotal tumors and pseudotumors. RadioGraphics 30(3):665-683
8. Guthrie JA, Fowler RC (1992) Ultrasound diagnosis of testicular tumours presenting as epididymal disease. Clin Radiol 46(6):397-400

9. Rana S, Sharma P, Singh P, Satarkar RN (2015) Leiomyoma of scrotum: a rare case report. Iran J Pathol 10(3):243-247

10. Kim NR, Sung CO, Han J (2003) Bizarre leiomyoma of the scrotum. J Korean Med Sci 18(3):452-454

\section{Publisher's Note}

Springer Nature remains neutral with regard to jurisdictional claims in published maps and institutional affiliations.

\section{Submit your manuscript to a SpringerOpen ${ }^{\circ}$ journal and benefit from:}

- Convenient online submission

- Rigorous peer review

- Open access: articles freely available online

- High visibility within the field

- Retaining the copyright to your article

Submit your next manuscript at $\mathbf{s p r i n g e r o p e n . c o m ~}$ 